\title{
The effects of father's worklessness on young adults in the UK
}

Wouter Zwysen

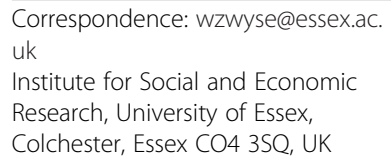

Correspondence: wzwyse@essex.ac. uk

Institute for Social and Economic Research, University of Essex, Colchester, Essex CO4 3SQ, UK

\begin{abstract}
Using the United Kingdom household longitudinal study (UKHLS), this paper shows the effect of experiencing a father being out of work on a range of labour market outcomes as young adults. Children of non-working fathers work less and are less satisfied while working despite similar wages and contract types. A sensitivity analysis shows that this effect of father's worklessness is robust to the inclusion of strong unobserved confounders, indicating non-spuriousness. Support is found for the idea that young adults who grew up experiencing their father's worklessness develop a different, less negative attitude, towards being out of work.

JEL codes: J620, J640, J30

Keywords: Intergenerational transmission; Worklessness; Family background; Job quality
\end{abstract}

\section{Introduction}

The transmission of economic disadvantage over generations has gained increasing political and academic attention. It is important to understand the mechanisms through which young adults are affected by their background, especially in more difficult economic times. This article studies the effect of paternal worklessness on different aspects of young adult's labour market experiences in the UK.

Most literature on social mobility focuses on intergenerational mobility in occupations or wages, ignoring unemployment and alternative aspects of job quality (Bowles et al. 2005; Erikson and Goldthorpe 2010; Lee and Solon 2009). A smaller literature shows a positive correlation between unemployment or worklessness of children and their parents (Ekhaugen 2009; Macmillan 2010; O’Neill and Sweetman 1998). These topics have been studied separately up until now, while unemployment and low job quality are dynamically linked (Stewart 2007).

Understanding the mechanisms through which experiencing a father's worklessness can influence their children's further labour market outcomes is necessary to tackle the continuation of disadvantage over generations. Human capital investment, mental health and wellbeing, attitudes and a sense of stigma towards being out of work are mentioned in the literature as possible mediators, but they have not yet been tested (Ekhaugen 2009; Macmillan 2010). A notable exception is the study by Macmillan (2013). She studies the role of several mediating mechanisms on the transmission of worklessness using the British cohort study.

(C) 2015 Zwysen; licensee Springer. This is an Open Access article distributed under the terms of the Creative Commons Attribution License (http://creativecommons.org/licenses/by/4.0), which permits unrestricted use, distribution, and reproduction in any medium, provided the original work is properly credited. 
To study the mechanisms of how paternal worklessness affects children further, this study estimates the differences between advantaged and disadvantaged young adults on the probability of working as well as on the quality of the job. By using the "Understanding Society" dataset, a large panel study, more detailed prospective information on employment characteristics is available than in the often used cohort studies.

A disadvantaged family background is associated with a lower probability of being employed, as shown in previous work, but is also associated with working fewer hours and being less satisfied with work. The type of contract and wages do not seem to be affected by having experienced paternal worklessness however. By studying these different outcomes together, the mechanisms are clearer, improving upon the literature. Young adults who experienced father's worklessness are compared to similar young adults whose fathers worked but had, on average, low wages. By using this control group, it is unlikely that the differences are driven by financial capability and different possibilities of investing in children's human capital. Differences in human capital, as well as lower cognitive and non-cognitive skills would also affect wages and type of contract, making this a less likely story. This paper suggests that young adults whose fathers have been workless while growing up experience worklessness differently and less negatively than those who lack this experience. This might lead to longer unemployment during the search for a good job (Tatsiramos 2006). This suggests further research into the experiences of work and worklessness is required.

\section{Worklessness and disadvantage over generations}

Most of the literature on social mobility has focused on the transmission of social class, status or income across generations (Erikson and Goldthorpe 2010; Jonsson et al. 2007; Mazumder 2005; Solon 1999). These measures are only available for those who are working however. A small, mostly economic literature consistently shows a positive relation between the labour market attachment of fathers and their children (Johnson and Reed 1996; Macmillan 2010 2013; O’Neill and Sweetman 1998; Payne 1987). These articles mainly focused on establishing a causal relation rather than working out the separate mediating mechanisms, with the exception of Macmillan (2013). She finds that parental worklessness increases the probability that their children will experience some time being out of work. Around $12 \%$ of this effect can be explained through cognitive and non-cognitive skills, education and attitudes.

While the literature consistently finds that children of non-working fathers are less likely to be employed themselves, not much is known about their work when employed. Schoon et al. (2012) showed that experiencing father's worklessness is associated with educational outcomes and labour market aspirations, but they did not look at labour outcomes. Several other outcomes besides the child's employment can be influenced by father's worklessness.

This article addresses two aspects of the intergenerational transmission of economic disadvantage by looking at the effect of father's worklessness on young adults' labour supply and the characteristics of their work when employed. First of all, the effect of experiencing a father being out of work at age 14 on the probability of employment, the hours worked and whether the child works part-time are studied. Following the idea of dual labour markets, children of non-working fathers are more likely to find themselves in less desirable jobs. The primary labour market offers better-paid jobs 
where employers aim to retain their employees for a longer time. The secondary segment consists of less desirable jobs with fewer prospects (Leontaridi and Sloane 2001). A less desirable position is marked by lower wages and less security through a fixedterm contract. The final outcome is the children's satisfaction with their job which captures a more subjective aspect of job quality. An understanding of the different aspects of work that are affected by paternal worklessness leads to a better knowledge of the mediating mechanisms.

This paper focuses on testing the mediation mechanisms through which paternal worklessness affects the young adult's probability of employment and job quality. No specific causal method is used, but a sensitivity analysis is carried out to test the robustness of the estimates to endogeneity, showing strong robustness.

\subsection{Mechanisms through which father's worklessness affects children}

There are several possible reasons why children of non-working fathers are more at risk of not working themselves. First of all, parents and children share many characteristics that may affect their labour market experiences. O'Neill and Sweetman (1998) named this a transmission of preferences or a transmission of constraints. Being out of work is rarely the only type of disadvantage to which these children are exposed while growing up. Other adversities such as parental ill-health, low education or poverty often accompany it (Schoon et al. 2012). A qualitative study by Shildrick et al. (2012) tested the presence of a 'culture of worklessness' within households where parents and their children experienced long periods out of work. They found no evidence for such a culture and found that the persistence of worklessness was often caused by multiple deprivations and not by a cultural adherence to worklessness.

Job loss is associated with a loss in income which can influence the human capital investment in children. This then lowers their labour market success (Becker and Tomes 1994). Parental poverty rather than worklessness is therefore thought to drive the association of disadvantage over generations. If this holds, children of non-working fathers are expected to be employed less often or for fewer hours as well as to face worse conditions in terms of wage and job security than children of working fathers. By only comparing children whose fathers did not work to those whose fathers worked in a low paying job, the difference in financial means is diminished. Parental job loss could also lower children's success on the labour market by lowering their wellbeing and mental health through increased stress in the household. Unemployment in the household is shown to lead to lower wellbeing for the children (Burchell 1994; Larson et al. 1994). This lower psychological wellbeing of the child may then influence their own labour market experience as lower mental health is associated with a decrease in employment probability (Frijters et al. 2010).

A young adult whose father did not work may then experience lower psychological wellbeing, and this in turn impacts his/her employment probability and job quality. This pathway leads to the same expected results as in the case of lower human capital investment, namely their childhood experience of worklessness leads them to be less successful on the labour market overall.

A final pathway considered here is that the experience of worklessness of the parent influences the child's attitudes. First of all, a young adult who experiences parental worklessness could be less affected by the stigma attached to not working (Ekhaugen 2009; Macmillan 2010). By being less unhappy when out of work themselves, they may 
therefore feel less pressure to accept just any job. If experiencing a father's worklessness changes the evaluation of work and their sense of stigma, these young adults would work less or less often but would not face worse conditions when working. Ekhaugen (2009) suggests that seeing a father not working may also lead the children to try harder to avoid unemployment. However, the literature has not shown negative correlations in worklessness between generations.

Attitudes towards being out of work are not measured directly in the dataset used here. It is well established however that not working, either in inactivity or unemployment, is associated with lower life satisfaction (Green 2011). This decrease in life satisfaction when not working can indicate the importance of work. If children of workless parents do not derive as much of their self-value from work, and if not working carries less of a stigma, they would suffer a smaller decrease in life satisfaction when out of work than children whose fathers did work.

Father's worklessness may also influence their children's experiences on the labour market through effects on general attitudes and behaviour. Experiencing parental worklessness impacts aspiration and attitudes towards education and the labour market (Schoon et al. 2012). Armstrong (2012) showed that children's belief in a just world influenced their education decisions, and this was heavily determined by their parent's belief that hard work pays off. An experience such as being out of work could strongly impact this belief. Dohmen et al. (2012) show that parents and their children share a propensity to trust people or take risks, which has strong effects on labour market outcomes. These attitudes are formed while growing up and can be influenced by witnessing a father's worklessness. These general attitudes and beliefs would influence the labour supply as well as the working conditions through lowering motivation and reducing the general labour market success of these young adults.

The literature also suggests that fathers who are out of work have less useful social networks in terms of aiding job search. As many young adults rely on their parents' networks in their early career, children whose father did not work would be at a comparative disadvantage to those whose father worked and maintained a network (Corak and Piraino 2011; O’Neill and Sweetman 1998). As social networks depreciate when out of work and recover when re-employed, these would only mediate if the parental unemployment occurred shortly before the child's job search and are therefore not considered here (Bramoullé and Saint-Paul 2010).

\section{Data and methods}

Data from the UK Household Longitudinal Study, or "Understanding Society", (UKHLS) is used. This is a large household panel survey of around 40,000 households in the United Kingdom (2013). The sample is restricted to respondents who answered in the first two waves (2009-2010 and 2010-2011) as some mediators were only asked in the first wave, and all outcomes were measured in the second wave. The initial response rate was $81.8 \%$ and further attrition at wave 2 was $22.7 \%$ (Lynn et al. 2012). All outcomes are weighted to account for this attrition. The sample consists of 3,965 respondents. They were 16-30 years old in the first wave and not in full-time education in the second wave. Literature on scarring shows that the labour market experiences during this early period can have long-lasting effects on the later career (Gregg and Tominey 2005; Mavromaras et al. 2013). 
The UKHLS has not yet been used for the study of the effects of paternal worklessness as most British studies on this topic used the cohort studies. The UKHLS is used here because it contains information on variables concerning mental health and well-being, which allow the study of this mediating mechanism. It also allows richer information on the type of employment through prospective questions about job characteristics, as compared to retrospective employment histories. This study complements work using the cohort studies, such as Mavromaras et al. (2013).

In addition to the UKHLS, the quarterly Labour Force Survey (LFS) for the United Kingdom is used from 2002 through to 2010. The LFS is a nationally representative sample in the UK with about 60,000 households, maintained by the Office for National Statistics (ONS). It is used to calculate median hourly wages for different groups.

The father's working status when the child is 14 is measured through three categories depending on whether the father worked and in what 3-digit occupation he worked at age 14 if he was employed. These occupations are divided in two groups. Based on the LFS, the weighted median hourly wage by occupation is calculated and ranked quarterly. These rankings are averaged between 2002 and 2010. Occupations with an average rank below the first quartile are classified as lowpaying since the median wage in that occupation was among the lowest $25 \%$. Of the 3,965 respondents, 472 (12\%) reported having a father who did not work at age 14 and 949 (24\%) had a father who was working in an occupation within the lowest quartile of median wage. The results are found to be robust to changes in the threshold of a low wage occupation from the lowest quartile to the lowest half and the lowest decile.

In order to estimate the effect of having a father who did not work at age 14, the counterfactual of their outcomes had their father worked is needed. The difference between the observed outcome and these potential outcomes for children of workless fathers is the average effect of treatment for the treated (ATT) (Schafer and Kang 2008). These potential outcomes can be estimated by predicting the outcome for children whose fathers did not work using the prediction equation from an appropriate regression model for the relevant outcome in the control group (Rubin 1979; Schafer and Kang 2008). This prediction is the estimate of the potential outcome. The difference between the observed outcome for the treated group and their estimated potential outcomes is tested using a paired sample Ttest. Equation 1 presents the calculation of the average treatment effect, with $\mathrm{T}$ indicating treatment and $\mathrm{Y}$ indicating the outcome for individual ' $\mathrm{i}$ '. $\hat{Y}_{0}$ indicates the predicted outcome for the treated group based on the equation estimated in the control group $(T=0)$. The control group are those whose fathers worked in lower paying occupations. Restricting the control group means that the conditions while growing up of those whose fathers did not work are not as big as when comparing them to everyone.

This method allows for a non-additive treatment effect and for possibly different returns to other characteristics, whereas including an indicator variable for paternal worklessness in a linear regression might not capture the full effect.

$$
A T T=\frac{\sum_{i} T_{i}\left(Y_{i}-\widehat{Y_{i 0}}\right)}{\sum_{i} T_{i}}
$$




\subsection{Labour market outcomes}

The effect of paternal worklessness is estimated on eight different outcomes. The sample varies depending on whether employment probability or job characteristics are the outcome. The final sample for employment probability consists of 472 children whose fathers did not work and a control group of 856 young adults whose fathers worked in a lower paying occupation. When studying job characteristics, the sample consists of 259 young adults whose fathers did not work and a control group of 622 young adults.

The first outcome is the young adult's employment probability. The counterfactual is estimated through a binary logistic regression. Respondents work if they had paid work in the last week or if they had a paid job despite not working in the last week. All other cases are classified as out of work, and respondents in full-time education are not included. 3,019 (76.1\%) of the respondents in the full sample were working. This includes the self-employed. Since a father and child can share many characteristics that make them both more likely to be employed or not, the following control variables are included. First of all, the respondent's gender, age and highest obtained educational qualification are controlled for. Whether the respondent is white or non-white and whether the respondent speaks English as a native language are also taken into account. Variables indicating whether the respondent is cohabitating or married and whether (s)he has children are included as this may influence labour supply. Having poor health was controlled for as health is related to the transmission of socio-economic status (Bianchi et al. 2005; Smith 2004). Variables measuring how often the respondent sees their father and whether the child lived with the father at age 16 are included to capture the strength of the relationship between father and child. To account for the general employment situation when the child was 14 years old, the UK-wide unemployment rate in the year the child was 14 years old, acquired from the OECD (http://stats.oecd.org/\#, accessed on 31/04/2013), was included as this could influence the children's attitude towards unemployment (Ochsen and Welsch 2011). Father's current age and whether the father and mother had a higher educational degree are included since parental education may influence the child's labour market outcomes (Andersen 2011).

Hours spent working, on average, each week is another dependent variable capturing labour supply. This outcome is measured through ordinary least squares (OLS) with the same control variables as when estimating the probability of being employed.

The final indicator of labour supply is a dummy variable for working part-time. This is estimated using a binary logistic regression with the same control variables as when estimating the probability of employment.

Working on a fixed-term contract may increase job insecurity and is therefore an important part of the quality of the job. The potential outcome is estimated using a binary logistic regression on a dummy variable using all control variables as above, with the exception of whether the respondent cohabitates or has children. Socio-demographic background, family background and relation to father as well as unemployment rate at age 14 are still included.

In order to assess the quality of employment, a dummy indicating whether the respondent's earnings are lower than those of his/her peers is used. This relative wage can be an important indicator of job quality. It compares the individual wage to an appropriate peer group which the person might take as a comparison as well. The median gross hourly wage is calculated by age category $(16-19 ; 20-25 ; 26-30)$, gender and 
highest educational qualification. This is calculated in the LFS from 2009 to 2010, weighted appropriately. A dummy variable indicates that the respondent's gross hourly wage, calculated from the UKHLS, lies below the nationally representative median hourly wage for people of similar age, gender and educational qualifications. The model is estimated through a binary logistic regression on all controls except cohabitating and being a parent. These two demographic variables are not thought to be important in determining the relative state of hourly wage. Working on a fixed-term contract and working part-time are also included as controls as someone's position in the wage distribution may depend on their type of contract.

The respondent's relative wage position was also calculated with regards to the hourly wage by age category, gender and 3-digit occupation, again using the LFS. This indicates that the respondent has a wage in the lower half of earnings compared to people of the same age and gender who work in the same occupation. The counterfactual is estimated similarly to the wage position given age, gender and education.

The logarithmic transformation of the child's monthly labour market outcomes serves as a straight-forward measure of labour market success. It relates directly to the financial dimension of job quality (Kalleberg 1977). The counterfactual labour market income for children whose fathers did not work is estimated through an OLS regression of the logarithm of gross monthly labour market income on all control variables that are used in estimating whether someone works on a fixed-term contract, with the addition of the average hours worked per week.

The final labour market outcome is the self-reported job satisfaction of working that respondents indicate about how they experience their work (Kalleberg 1977). Respondents in the UKHLS are asked how satisfied they are with their job and can respond from 1 , completely dissatisfied, to 7 , completely satisfied. If respondents reported to be somewhat dissatisfied (3) or less, this is classified as being dissatisfied on a dummy variable. The counterfactual job satisfaction is estimated using a binary logistic regression using all controls used for monthly wage with the inclusion of all other labour market outcomes. This variable complements the more objective job characteristics by adding the respondent's evaluation of the job. It may indicate different expectations of a job and therefore different evaluations of the available work conditions on average.

Ideally the analyses should be carried out separately for men and women. This strongly reduces the sample however, which is why gender is only controlled for. As a robustness test, the analyses were separated by gender, showing small differences.

\subsection{Mediation}

Paternal worklessness is expected to affect a young adult's probability of employment at least partly through some other mediating variables. In this analysis, only employment probability is estimated as an outcome. Mental health, wellbeing and attitudes were tested for their role in the transmission of worklessness.

These concepts mediate the effect of father's worklessness if they are influenced by father's worklessness and in turn affect the child's employment probability, when controlling for father's worklessness (Mackinnon and Dwyer 1993). The total effect of father's worklessness on the probability of employment is decomposed into a direct effect and an indirect effect. This indirect effect is the part that is accounted for by the 
mediator. This decomposition is not straight-forward when it involves binary outcomes (Breen et al. 2013).

In this paper, an extension of the method explained above using counterfactuals is applied. First of all, the effect of paternal worklessness on the mediating concept is estimated as the difference between the average value of that variable in the treatment group and the counterfactual based on a prediction equation in the control group. This difference indicates the extent to which growing up with a workless father affects that mediator.

We are interested in whether these mediators explain some of the effect of growing up with a workless father on the employment probability. To do this the average proportion of employment in the treatment group is compared to two counterfactuals. The first counterfactual is estimated without accounting for the value of the mediator. This indicates the total effect. A second counterfactual is based on a prediction equation in the control group where the mediator is included. The effect of paternal worklessness is then calculated based on the two counterfactuals. The difference between the effect of paternal worklessness when taking the mediating concept on board and ignoring it indicates the role played by that concept. The relative difference between the two indicates the percentage of the total effect due to an indirect effect through the mediator.

The first mediator is the respondent's psychological wellbeing. It is measured through two dummy variables (Warr 1990). The first one indicates the respondent scores in the top quartile of the general health questionnaire (GHQ). This is a validated scale for mental health status, where a higher score indicates higher probability of mental problems (Goldberg et al. 1997). Another dummy indicates that the respondent felt completely, mostly or somewhat dissatisfied with life in general. The correlation between the two dummies is 0.31 and significant at $\mathrm{p}<0.05$, which is not too high.

The second mediator consists of attitudes or non-cognitive skills. Seven indicators measure this. One is a factor built from seven items that indicate a positive outlook on life and self-confidence. These items are: 'feeling optimistic about the future'; 'feeling useful'; 'feeling relaxed'; 'dealing with problems well'; 'thinking clearly'; 'feeling close to others' and 'able to make up own mind'. The scale has a Cronbach's alpha of 0.86 , and a higher score indicates a more positive outlook. Sense of control is measured through three dummy variables that indicate that someone feels moderate or strong powerlessness regarding life or occurrences at home and whether the respondent feels overwhelmed with demands (Armstrong 2012; Groves 2005). These dummies correlate at 0.38 at most, which is not too high. Attitudes towards risk and trusting people can be influenced by parental experiences and influence economic outcomes (Dohmen et al. 2012). A dummy indicating the respondent does not believe most people can be trusted and two variables ranging from 0 to 10 capturing whether the respondent is prepared to trust strangers and prepared to take risks in general are included. These three variables correlate at 0.38 at most.

To test whether respondents whose fathers did not work experience worklessness differently than their peers whose fathers worked, the association of being out of work with overall wellbeing is studied. If young adults whose fathers did not work experience worklessness as less negative, a weaker association between being out of work and dissatisfaction with overall life is expected for these respondents. 
Being dissatisfied with life is logistically regressed on the control variables used for the employment equation. The respondent's employment status in both waves, the father's employment status when the father was 14 years old, and the interaction of the respondent's employment status in the second wave and the father's employment status are also included. If being out of work is experienced differently in terms of dissatisfaction with life by respondents depending on their father's employment status while growing up, the interaction term will be significant.

\subsection{Missing observations}

There are many missing observations among these variables, which is problematic as the sample is quite small. To deal with the missing data, 50 multiple imputations through chained equations are used (Royston and White 2011). All control variables as well as the mediators and labour market outcomes in waves 1 and 2 are used in the imputation model. Multiple imputation assumes that the data are missing at random, conditional on all variables that are used in the imputation model. This is superior to a complete cases analyses if responses are not missing completely at random (Enders 2010).

\section{Results}

\subsection{Estimated treatment effect of experiencing father's worklessness}

Table 1 presents results where children whose fathers did not work are compared to their counterfactual outcomes had their father worked in a lower paying occupation. The full regression model is shown in Additional file 1: Appendix.

Experiencing paternal worklessness lowers the probability of being employed by 14 percentage points. When employed, having a workless father is associated with working 3 hours less per week and being 10 percentage points more likely to work part-time. Young adults whose father was out of work at age 14 are 6 percentage points more likely to be dissatisfied while working, even when controlling for all the labour market outcomes studied here. This may indicate a different evaluation of objective job

Table 1 Effect of father not working rather than working in lower paid occupation

\begin{tabular}{llll}
\hline Outcome & $\begin{array}{l}\text { Average observed } \\
\text { (Std. Error) }\end{array}$ & $\begin{array}{l}\text { Average counterfactual } \\
\text { (Std. Error) }\end{array}$ & $\begin{array}{l}\text { Difference (Std. } \\
\text { Error) }\end{array}$ \\
\hline Working & $0.55(0.02)$ & $0.69(0.01)$ & $-0.14(0.02)^{* * *}$ \\
Work part-time & $0.37(0.03)$ & $0.27(0.01)$ & $0.10(0.03)^{* * *}$ \\
Hours/week & $29.55(0.73)$ & $32.79(0.24)$ & $-3.23(0.68)^{* * *}$ \\
Low job satisfaction & $0.18(0.03)$ & $0.12(0.01)$ & $0.06(0.03)^{* *}$ \\
Fixed-term contract & $0.13(0.02)$ & $0.10(0.01)$ & $0.03(0.02)$ \\
Low hourly wage given occupation & $0.56(.04)$ & $0.59(0.01)$ & $-0.03(0.04)$ \\
Low hourly wage given education & $0.62(0.04)$ & $0.60(0.01)$ & $0.02(0.04)$ \\
$\begin{array}{l}\text { Logarithm of gross monthly labour } \\
\text { market income }\end{array}$ & $6.79(0.05)$ & $6.85(0.04)$ & $-0.05(0.04)$ \\
$\begin{array}{l}\text { Gross monthly labour market } \\
\text { income (calculated) }\end{array}$ & $£ 891.6$ & $£ 941.1$ & $£ 49.5$ \\
\hline
\end{tabular}

**: $p<0.05$; **: $p<0.01$, working or not is estimated on 472 treated respondents and 856 controls, while job characteristics are estimated for 259 young adults whose father did not work with 622 young adults whose fathers worked in a lower paying occupation. 
characteristics, or it may indicate that there are some aspects, such a job security or environment in which they work, that are not measured here but are worse for respondents whose fathers did not work. There are no statistically significant differences in the probability of working on a fixed-term contract, in hourly wage or in relative position of the hourly wage.

Having a father who did not work is associated with lower labour supply and less satisfaction at work than having a father who worked in a low-paying occupation. This is interesting as there are no significant effects on the quality of work in terms of absolute or relative pay or job contract once employed. This pattern of effects suggests that children whose fathers did not work are not necessarily seen as less skilled or less able as their wages and contract types are similar. It is, therefore, unlikely that the effect is due to human capital or differences in skills.

Growing up with a father who did not work at age 14 reduces the probability of being employed as a young adult by approximately 14 percentage points. Table 2 presents the proportion that can be explained through differences in wellbeing or attitudes. It presents the effect father's worklessness at age 14 has on the mediating variable. It also shows the effect of paternal worklessness on being employed, estimated at -0.137 , after accounting for the mediator, and indicates what proportion of this effect is explained.

Having a father who did not work rather than working in a low-paid job is associated with having lower life satisfaction, feeling less control over life and at home and feeling overwhelmed by demands. It is also linked with being less trusting and having a less positive outlook on life. These concepts do not explain a substantial part of the total effect however. The most substantial contribution is made by including the GHQ score, indicating a low mental health. This reduces the effect of paternal worklessness by around $10 \%$. Growing up with a workless father does not contribute to mental health however, indicating that this does not mediate (Macmillan 2013). The two concepts indicating well-being explain a similar amount as the attitudes taken together, namely around $8 \%$. When all characteristics are taken together, a bit less than $11 \%$ is explained. This is still a small amount, but it is comparable to the 12\% Macmillan (2013) finds using the BCS. She explains the intergenerational association in worklessness using non-cognitive skills, cognitive skills, behavioural outcomes and educational outcomes. Non-cognitive skills are most important in her model and play a similar role to the attitudes used here. This paper suggests that psychological wellbeing may also play a role.

A final hypothesized pathway here is that children whose fathers did not work experience being out of work less negatively. If children of workless fathers suffer less from being out of work, a lower association between life satisfaction and being out of work is expected for them than for children whose fathers worked. This was tested through regressing being dissatisfied with life on the interaction term between having a job and father's employment status at age 14. A different experience of worklessness should show as a significant interaction term. Table 3 presents these coefficients in odds ratios.

The interaction term indicates that the association of employment and dissatisfaction with life differs significantly for respondents depending on whether their father worked at age 14. Children whose fathers worked have odds of being dissatisfied with life when employed that are 0.64 times those of when they do not work, while this is 1.62 [0.61*2.55] for children whose fathers did not work. Respondents whose father did not 
Table 2 mediation between father's worklessness and respondent's employment

\begin{tabular}{llll}
\hline Mediators & $\begin{array}{l}\text { Effect father not working } \\
\text { on mediator (s.e.) }\end{array}$ & $\begin{array}{l}\text { Direct effect father not working, } \\
\text { accounting for mediator (s.e.) }\end{array}$ & $\begin{array}{l}\text { \% effect father not } \\
\text { working explained }\end{array}$ \\
\hline $\begin{array}{l}\text { GHQ score } \\
\text { high }\end{array}$ & $0.00(0.02)$ & $-0.12(0.02)^{* * *}$ & $10.2 \%$ \\
$\begin{array}{l}\text { Low life } \\
\text { satisfaction }\end{array}$ & $-0.09(0.02)^{* * *}$ & $-0.14(0.02)^{* * *}$ & $1.5 \%$ \\
Wellbeing & & $-0.13(0.02)^{* * *}$ & $8.8 \%$ \\
$\begin{array}{l}\text { Low trust } \\
\text { Control over }\end{array}$ & $-0.08(0.03)^{* * *}$ & $-0.14(0.02)^{* * *}$ & $-0.7 \%$ \\
$\begin{array}{l}\text { life } \\
\text { Control at } \\
\text { home }\end{array}$ & $-0.11(0.02)^{* * *}$ & $-0.14(0.02)^{* * *}$ & $-1.5 \%$ \\
$\begin{array}{l}\text { Experience } \\
\text { many demands }\end{array}$ & $-0.16(0.02)^{* * * *}$ & $-0.14(0.02)^{* * *}$ & $0 \%$ \\
$\begin{array}{l}\text { Positive } \\
\text { outlook }\end{array}$ & $-0.14(0.04)^{* * *}$ & $-0.14(0.02)^{* * *}$ & $-0.7 \%$ \\
$\begin{array}{l}\text { Prepared to } \\
\text { take risks }\end{array}$ & $-0.17(0.14)$ & $-0.13(0.02)^{* * *}$ & $7.3 \%$ \\
$\begin{array}{l}\text { Risk to trust } \\
\text { Attitudes }\end{array}$ & $0.01(0.13)$ & $-0.13(0.02)^{* * *}$ & $3.6 \%$ \\
\hline
\end{tabular}

***:p $<0.01$, controlled for gender, age, education, race, born in UK, speaking English, cohabitation, having children, having poor health, contact with father, lived home at age 16, unemployment rate at age 14, age of father, father's education, mother's education, on respondents whose father did not work or worked in a lower paying occupation. Standard errors are presented in parentheses. The sample consists of 472 young adults whose fathers did not work and the counterfactuals are constructed based on 856 young adults whose fathers worked in lower paying occupations. The direct effect is the difference between the observed proportion of employment and the counterfactual, taking the value on the mediator into account. The \% effect father explained is the \% change in the estimated effect of father's worklessness when the mediator is taken into account as opposed to when it is left out.

work at age 14 are therefore on average more dissatisfied with their life when employed than when out of work. This may indicate that children whose fathers did not work at age 14 are already more familiar with being out of work and therefore suffer less when out of work themselves. This decreased stigma might then affect labour supply as remaining out of work while looking for a job is experienced less negatively (Tatsiramos 2006). Another option is that they face worse conditions on average, resulting in this being worse.

\subsection{Sensitivity to inclusion of a binary unobserved confounder}

Fathers and children share many unobserved characteristics that may influence their labour market success. This could be intelligence or motivation, for instance (Ekhaugen 2009; Macmillan 2010). While the possible endogeneity this entails is not dealt with directly, the robustness of the results to unobserved characteristics is tested through a sensitivity analysis.

Table 3 Difference in experiencing being out of work (odds ratio)

\begin{tabular}{ll}
\hline $\mathbf{N}=1,158$ & Dissatisfied with life (s.e.) \\
\hline Have a job & $0.63(0.18)$ \\
Father did not work at age 14 & $0.61(0.16)$ \\
Interaction employment and father's worklessness & $2.55(0.86)^{* * *}$
\end{tabular}

***: $\mathrm{p}<0.01$, weighted and controlled for gender, age, education, race, born in UK, speaking English, cohabitation, having children, having poor health, contact with father, lived home at age 16, unemployment rate at age 14, age of father, father's education, mother's education and employment in wave 1 on respondents whose father did not work or worked in a lower paying occupation. Standard errors are presented in parentheses. 
This form of sensitivity analysis makes assumptions about the type of unobserved characteristics, such as the relation with the independent variable of interest and the strength of the relation with the outcome, to estimate the true effect of the treatment, correcting for the confounder. By changing these characteristics, the plausibility of an unobserved covariate of sufficient strength to change the conclusions regarding the treatment effect can be evaluated. We use a method first proposed by Lin et al. (1998). They show a straight-forward correction factor to adjust the estimated effect of having a father who did not work, based on three parameters: first, the odds of the unobserved binary confounder on the outcome $(\Gamma)$ in the treatment (1) and control group (0), which can be assumed to be the same; second, the probability that the confounder is present in the treatment group (P1); and third the probability that the confounder is present in the control group (P0). They show analytically that the true effect of the treatment, $R$, equals $R^{*}$, the observed treatment effect in a reduced model without unobserved covariates divided by an adjustment factor A. Equations 2 and 3 present this (Lin et al. 1998). The same adjustment factor can be used on the boundaries of the confidence interval so we can assess the significance of the results. This adjustment is applied to the logistic regression coefficients of having a father who did not work rather than working in a lower paid occupation on the probability of being employed. Groenwold et al. (2010) state that this method is a more conservative estimate as the correlations between the unobserved covariates and the observed covariates are not taken into account.

$$
\begin{aligned}
& R={ }^{R} * / A \\
& A=\frac{\Gamma_{1} \mathrm{P}_{1}+\left(1-P_{1}\right)}{\Gamma_{0} \mathrm{P}_{0}+\left(1-P_{0}\right)}
\end{aligned}
$$

The true effect of father's worklessness on their children's probability of employment is assumed to depend on the control variables but also on an uncontrolled characteristic. This confounder has a given positive association with the child's employment probability and a negative association with the probability of having a workless father (Groenwold et al. 2010; Lin et al. 1998).

Assuming that someone with the unobserved confounder has odds that are twice as high of being in work than someone without $(\Gamma=2)$, the unobserved confounder would have to be very unequally distributed to make the effect of having a father who did not work insignificant. If all of those whose father worked in a lower paying job would have the unobserved confounder, at most $10 \%$ of those whose father did not work can have the unobserved confounder for the effect to no longer be significant. As the model controls for education and other important characteristics such a disparity is quite unlikely. Assuming $\Gamma$ to be 2 means that the unobserved confounder would have a stronger effect than whether the father had a higher degree or not (odds ratio of 1.17). Even if the association of the unobserved confounder with employment probability and the father's worklessness is as strong as the difference between having no qualifications and a degree, there would still be a significant negative effect of father's worklessness on the young adult's probability of being employed. While this does not mean there are no unobserved heterogeneity issues, these tests do indicate that the results are robust to implausibly strong confounders. 


\subsection{Different specifications}

Several robustness tests in which one specific operationalisation is changed were carried out. The results are shown in Additional file 1: Appendix. As already described, the threshold of a low paying occupation is changed from the lowest $25 \%$ to the lowest $50 \%$ and the lowest $10 \%$. Roughly the same effects as when using the lowest $25 \%$ are found. When the sample was restricted to only those people that are employed or unemployed, leaving out the inactive, the same results were found. This leaves 1,107 respondents, of whom $78 \%$ are employed. Separating the analyses by gender, it is found that father's worklessness is associated with lower employment probabilities and fewer hours for both. Sons of workless fathers were more likely to work part-time and daughters of working fathers were more likely to be dissatisfied with their job. As a final test, propensity score matching on the nearest neighbour was used to estimate the counterfactual outcomes rather than regression techniques. This method has been shown to be less biased than regression techniques if large initial biases exist or if the function relation between covariates and outcomes is incorrectly modelled (Caliendo and Kopeinig 2008; Schafer and Kang 2008). To conclude, the effect of father's worklessness on the probability of being employed is robust and strong. The employed children of workless fathers are consistently less satisfied with their jobs than they would have been if their father had worked.

\section{Discussion and conclusion}

The rising worklessness among young people highlights that studying job quality without taking employment into account misses a substantial aspect of economic disadvantage. Studying them separately obscures a part of the effect of early disadvantage, such as paternal worklessness. This paper shows that young adults whose father did not work when at age 14 are less likely to be employed themselves. When employed, they tend to work fewer hours and work part-time more often than their counterparts whose fathers did work. This difference remains even when comparing children whose fathers did not work with those whose fathers worked in a lower paying occupation.

Father's worklessness is not associated with having lower wages or less secure contracts. However, if a young adult's father did not work when they were younger, they are less likely to be satisfied with their job. This could indicate that employment itself is experienced differently as similar objective conditions in terms of contract type and wage coincide with lower job satisfaction if someone's father did not work rather than if the father was employed. Alternatively, the experienced jobs could differ between those whose fathers worked and those whose fathers did not in characteristics that are not observed.

Decreased wellbeing or differences in attitudes and behaviours account for at most $10 \%$ of the association between a father not working and his child being out of work at age 16-30. There is some indication that young adults whose fathers did not work experience being out of work differently. While being out of work is on average associated with higher dissatisfaction than working, this is actually the reverse for young adults whose fathers did not work. They are more likely to state being dissatisfied when employed than when out of work. Experiencing paternal worklessness could thus lead to a different evaluation of being out of work and the time that must be spent working.

This paper indicates the importance of taking family background into account when studying labour market experiences. It also shows that the high unemployment rates that occur now may have longer-term repercussions later on as these workless young 
adults have children of their own. A possible pathway through which experiences of worklessness while growing up can affect later labour market outcomes could be how work and being out of work is experienced. Experiencing paternal worklessness could affect the expectations of employment and the sense of failure when out of work, which could influence further labour market outcomes.

\section{Additional file}

Additional file 1: Appendix. Table S1. Regressions of labour market outcomes on control sample of fathers working in low paying occupations. Table S2. Results from different sensitivity analyses.

\section{Competing interests}

The IZA Journal of European Labor Studies is committed to the IZA Guiding Principles of Research Integrity. The author declares that he observed these principles.

\section{Acknowledgements}

This work has been made possible through a scholarship from the Economic and Social Research Council. The paper benefited from the comments of the anonymous reviewer and from comments at the Understanding Society conference in July 2013.

Responsible editor: Sara de la Rica

Received: 16 May 2014 Accepted: 8 October 2014

Published: 14 Jan 2015

\section{References}

Andersen SH (2011) Common genes or exogenous shock? Disentangling the causal effect of paternal unemployment on children's schooling efforts. Eur Sociol Rev 0:1-12

Armstrong A (2012) Belief in a just world and children's cognitive scores. Natl Inst Econ Rev 222:R7-R19

Becker GS, Tomes N (1994) Human Capital: A Theoretical and Empirical Analysis with Special Reference to Education. In: Becker GS (ed) Human Capital: A Theoretical and Empirical Analysis with Special Reference to Education. The University of Chicago Press, Chicago, pp 257-298

Bianchi SM, Casper LM, King RB (2005) Complex Connections: A Multidisciplinary Look at Work, Family, Health and WellBeing Research. In: Bianchi SM, Casper LM, King RB (eds) Work, Family, Health, and Well-Being. Lawrence Erlbaum Associates, Publishers, London, pp 1-17

Bowles S, Gintis H, Groves MO (2005) Introduction. In: Bowles S, Gintis H, Groves MO (eds) Unequal Chances: Family Background and Economic Success. Russell sage foundation and Princeton University Press, New York, Princeton and Oxford, pp 1-22

Bramoullé Y, Saint-Paul G (2010) Social networks and labor market transitions. Labour Econ 17:188-195

Breen R, Karlson KB, Holm A (2013) Total, direct, and indirect effects in logit and probit models. Sociol Methods Res 42:164-191

Burchell B (1994) The Effects of Labour Market Position, Job Insecurity, and Unemployment on Psychological Health. In: Gallie D, Marsh C, Vogler C (eds) Social Change and the Experience of Unemployment. Oxford University Press, Oxford, pp 188-211

Caliendo M, Kopeinig S (2008) Some Practical Guidance for the Implementation of Propensity Score Matching. J Econ Surv 22:31-72

Corak M, Piraino P (2011) The intergenerational transmission of employers. J Labor Econ 29:37-68

Dohmen T, Falk A, Huffman D, Sunde U (2012) The intergenerational transmission of risk and trust attitudes. Rev Econ Stud 79:645-677

Ekhaugen T (2009) Extracting the causal component from the intergenerational correlation in unemployment. J Popul Econ 22:97-113

Enders CK (2010) The Imputation Phase of Multiple Imputation. In: Applied Missing Data Analysis. The Guilford Press, New York, pp 187-216

Erikson R, Goldthorpe JH (2010) Has social mobility in Britain decreased? Reconciling divergent findings on income and class mobility. Br J Sociol 61:211-230

Frijters P, Johnston D, Shields M (2010) Mental Health and Labour Market Participation: Evidence From Iv Panel Data Models, IZA Discuss. Pap. Ser

Goldberg DP, Gater R, Sartorius N, Ustun TB, Piccinelli M, Gureje O, Rutter C (1997) The validity of two versions of the GHQ in the WHO study of mental illness in general health care. Psychol Med 27:191-197

Green F (2011) Unpacking the misery multiplier: How employability modifies the impacts of unemployment and job insecurity on life satisfaction and mental health. J Health Econ 30:265-276

Gregg P, Tominey E (2005) The wage scar from male youth unemployment. Labour Econ 12:487-509

Groenwold RHH, Nelson DB, Nichol KL, Hoes AW, Hak E (2010) Sensitivity analyses to estimate the potential impact of unmeasured confounding in causal research. Int J Epidemiol 39:107-117

Groves MO (2005) Personality and the Intergenerational Transmission of Economic Status. In: Bowles S, Gintis H, Groves MO (eds) Unequal Chances: Family Background and Economic Success. Russell sage foundation and Princeton University Press, New York, Princeton and Oxford, pp 208-231 
Johnson P, Reed H (1996) Intergenerational mobility among the rich and poor: results from the national chid development survey. Oxf Rev Econ Policy 12:127-142

Jonsson JO, Grusky DB, Carlo MD, Pollack R, Brinton MC (2007) Micro-Class Mobility Social Reproduction in Four Countries

Kalleberg AL (1977) Work values and Job rewards: a theory of Job satisfaction. Am Sociol Rev 42:124

Larson JH, Wilson SM, Beley R (1994) The impact of job insecurity on marital and family relationships. Fam Relat 43:138-143

Lee C-I, Solon G (2009) Trends in intergenerational income mobility. Rev Econ Stat 91:766-772

Leontaridi R, Sloane P (2001) Measuring the quality of jobs. Low Work Pap 7:5-42

Lin DY, Psaty BM, Kronmal RA (1998) Assessing the sensitivity of regression results to unmeasured confounders in observational studies. Biometrics 54:948-963

Lynn P, Burton J, Kaminska O, Knies G, Nandi A (2012) An Initial Look at Non-Response and Attrition in Understanding Society (Understanding Society at The Institute for Social and Economic Research)

Mackinnon DP, Dwyer JH (1993) Estimating mediated effects in prevention studies. Eval Rev 17:144-158

Macmillan L (2010) The Intergenerational Transmission of Worklessness in the UK. (working paper at Centre for Market and Public Organisation). p 52

Macmillan L (2013) The Role of Non-Cognitive and Cognitive Skills, Behavioural and Educational Outcomes in Accounting for the Intergenerational Transmission of Worklessness. (DoQSS Working Paper No.13-10). Department of Quantitative Social Science, Institute of Education, University of London, London, pp 1-40

Mavromaras K, Sloane P, Wei Z (2013) The Scarring Effects of Unemployment, Low Pay and Skills Under-utilisation in Australia Compared (Institute for the Study of Labor (IZA))

Mazumder B (2005) The Apple Falls Even Closer to the Tree Than we Thought: New and Revised Estimates of the Intergenerational Inheritance of Earnings. In: Bowles S, Gintis H, Groves MO (eds) Unequal Chances: Family Background and Economic Success. Russell sage foundation and Princeton University Press, New York, Princeton and Oxford, pp 80-99

McFall S (2013) Understanding Society - UK Household Longitudinal Study: Wave 1-2, 2009-2011, User Manual. University of Essex, Colchester

Ochsen C, Welsch H (2011) The social costs of unemployment: accounting for unemployment duration. Appl Econ 43:3999-4005

O'Neill D, Sweetman O (1998) Intergenerational Mobility in Britain: Evidence from Unemployment Patterns. Oxf Bull Econ Stat 60:431-447

Payne J (1987) Does unemployment Run in families? some findings from the general household survey. Sociology 21:199-214

Royston P, White IR (2011) Multiple imputation by chained equations (MICE): implementation in Stata. J Stat Softw 45:1-20

Rubin DB (1979) Using multivariate matched sampling and regression adjustment to control bias in observational studies. J Am Stat Assoc 74:318

Schafer JL, Kang J (2008) Average causal effects from nonrandomized studies: A practical guide and simulated example. Psychol Methods 13:279-313

Schoon I, Barnes M, Brown V, Parsons S, Ross A, Vignoles A (2012) Intergenerational Transmission of Worklessness: Evidence from the Millennium Cohort and The Longitudinal Study of Young People in England

Shildrick T, MacDonald R, Furlong A, Roden J, Crow R (2012) Are "cultures of worklessness" passed down the generations? Report. Joseph Rowntree Foundation, London

Smith JP (2004) Unraveling the SES-health connection. Popul Dev Rev 30:108-132

Solon G (1999) Intergenerational Mobility in the Labor Market. In: Handbook of Labor Economics. Elsevier, Amsterdam, pp 1761-1796

Stewart MB (2007) The interrelated dynamics of unemployment and low-wage employment. J Appl Econom 22:511-531

Tatsiramos K (2006) Unemployment Insurance in Europe: Unemployment Duration and Subsequent Employment Stability, IZA Discuss. Pap. Ser. no.2280., pp 1-43

Warr P (1990) The measurement of well-being and other aspects of mental health. J Occup Psychol 63:193-210

10.1186/2193-9012-4-2

Cite this article as: Zwysen: The effects of father's worklessness on young adults in the UK. IZA Journal of European Labor Studies 2015, 4:2

\section{Submit your manuscript to a SpringerOpen ${ }^{\circ}$ journal and benefit from:}

- Convenient online submission

- Rigorous peer review

- Immediate publication on acceptance

- Open access: articles freely available online

- High visibility within the field

- Retaining the copyright to your article

Submit your next manuscript at $\gg$ springeropen.com 